دراسه لبعض الاعمال المُعده لآله

$$
\text { البيانو واهميتها في التدريس }
$$

$$
\text { للارس المبتدئ }
$$

$$
\text { م/ ندا فؤاد عبد الحميد حجازي }
$$

معيدة بقسم التربية الموسيقية - كليه التربية

$$
\text { النوعية - جامعه الزقازيق }
$$

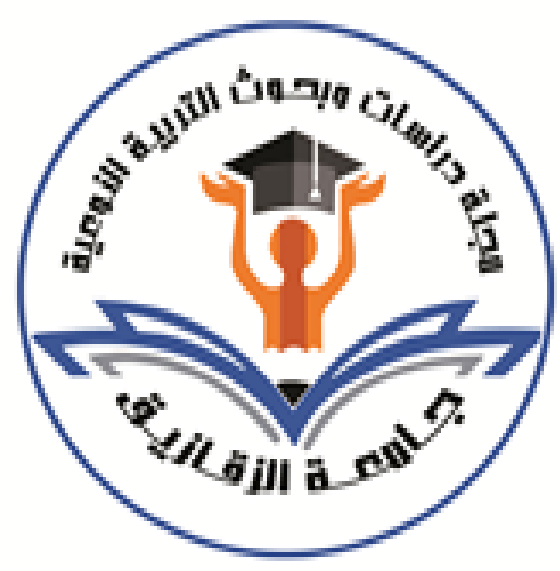

المجلة العلمية المحكمة لدراسات وبحوث التربية النوعية

المجلد السابع- العدد الثاني- مسلسل العدد (14)- يوليو 2021- الجزء الثالث

$$
\text { رقم الإيداع بدار الكتب } 24274 \text { لسنة } 2016
$$

ISSN-Print: $2356-8690$ ISSN-Online: $2356-8690$

https://jsezu.journals.ekb.eg موقع المجلة عبر بنك المعرفة المصري JSROSE@foe.zu.edu.eg

$$
\text { E-mail البريد الإكتروني للمجلة }
$$




\section{دراسه لبعض الاعمال المُعده لآله البيانو واهميتها في التدريس للارس المبتدئ}

$$
\text { م/ ندا فؤاد عبد الحميد حجازي }
$$

معيدة بقسم التربية الموسيقية - كليه التربية النوعية- جامعه الزقازيق

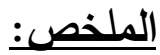

الموسيقى هي لغه الإحساس و الشعور وتعتبر فن من الفنون الجميله التى يعبر بها الانسان عن مكنون نفسه و عن رؤيته للاشياء، فهى علم له اصوله واساسياته ودراساته التى تفهمها جميع شعوب العالم باختلاف جنسياتهم واعمارهم ولغتهم، فتكوين الsفاهيم التعليميه تساعد على إكتساب المهارات العزفيه وتحقق انسب ظروف التعلم، تقصد هذه الدراسه الى تتاول بعض المقطوعات المُعده ذات الاهداف التعليمية المحدده كنماذج مرشده فى توجيه الدارس المبتدئ علي آله البيانو نحو استثمار المقطوعات العالميه التى تم اعدادها للعزف خصيصا على آله البيانو لتحقيق الاستفاده القصوى، وايضا تهدف الى ترغيب الدارس المبتدئ لدراسه الموسيقى العالميه والعزف علي آلة البيانو وذلك عن طريق تطبيق برنامج دراسى يصل الدارس المبتدئ من خلاله الى الاداء التقنى الجيد والمطلوب. الكلمات المفتاحية: آله البيانو - التدريس للدارس المبتدئ

المقدمة:

لقد اهتم الموسيقيون بالدارس المبتدئ في العزف علي مختلف الالات منذ زمن بعيد ، وتعد هذه هى المرحله كبدايه لكل متعلم للعزف التى يبدأ منها الجميع بمتطلباتها التى تستلزم تبسيط المعلومه وتسهيلها بالاضافه الى ضروره تكثيف المعلومات النظريه والادائيه والمهاريه التى يجب علي الدارس ادراكها ومن ثم استيعابها في اقل واقصر فتره ممكنه ، وذلك لتحقيق اكبر قدر ممكن من الاستفاده ، ولهذا يجب تحقيق التوازن بين اتجاهين اساسيين هما (التبسيطو الكثافه)، وتهيئه المجال الكافى امام الدارس المبتدئ لإستيعاب هذه المرحله بكل احتياجاتها ، مع العلم

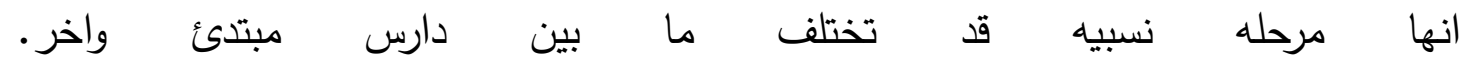
وفى مجال الإعداد الموسيقى اتجه المهتمون الى هذه الاحتياجات من خلال مقطوعات تعليميه تحتوي علي اهداف محدده مُعده عن مؤلفات عالميه لكبار الموسيقيين ولكن مع الحفاظ علي سمات وخصائص المؤلفه الاصليه ولحنها ،ومن هنا ترك الكثير من الموسيقيين بصمات واضحه هون 
فى هذا المجال ، تلخصت فى توظيف ما يرونه اساسيا لإعداد العازف الجيد من معارف نظرية ومهارات ادائية ضمن مقطوعات تعليمية مُعده خصيصا لآله البيانوومأخوذه من اعمال عالميه معروفة ، وتصنف على انها بسيطه فى ادائها وتتضمن كل واحده منها على مجموعه من المعارف والمهارات المناسبه لهذا المستوى ضمن رؤية تعليمية محدده مُعده بشكل مبسط عن المؤلفات العالمية.

مشكله البحث:

لاحظت الباحثه انه لايتم الاستفاده القصوي من الاعمال المُعده لآله البيانو فى توجيه عنايه الدارس المبتدئ وترغيبه فى دراسة كيفيه وطريقه العزف علي آله البيانو و الوصول به للاداء الجيد المطلوب ، على الرغم من كثره وتعدد المقطوعات العالميه التى قد تم اعدادها للعزف علي آله البيانو للمبتدئين والتى تتسم بالحانها المعروفه والمميزه واشتمالها ايضا على العديد من المفاهيم النظريه والمهارات العزفيه التى تم صياغتها خصيصا للوصول بالدارس المبتدئ الى مستوى تقنى محدد ومطلوب. اهداف البحث : (ه)

ا- التعرف على بعض المقطوعات الموسيقيه المُعده لآله البيانو (عينه البحث) وصولاً لاداء

$$
\text { تقنى جيد. }
$$

ץ- التعرف على بعض المفاهيم النظرية والمهارات العزفيه التى يمكن اكسابها للدارس المبتدئ من خلال عينه البحث.

اهمية البحث :

$$
\text { ترجع اهميه هذا البحث إلي: }
$$

1- جذب انتباه الدارس المبتدئ للموسيقى العالميه عن طريق المقطوعات العالميه المُعده

$$
\text { لآله البيانو - n }
$$

ץ- ابراز مدى الاستفاده القصوى التى يمكن تحقيقها هذه المقطوعات لدارسى آله البيانو •

\section{اسئلة البحث :}

1- ما هى المقطوعات الموسيقيه المُعده للآله البيانو(عينة البحث) وكيفية ادائها الاداء

$$
\text { التقنى الجيد؟ }
$$


ما هى المفاهيم النظريه والمهارات العزفيه التي يمكن اكسابها للدارس المبتدئ من خلال

$$
\begin{aligned}
& \text { عينة البحث؟ } \\
& \text { اجراءات البحث : }
\end{aligned}
$$

ا- منهج البحث : يتبع هذا البحث المنهج (التجريبي) لملائمته لاغراض البحث. ץ- عينه البحث : مقطوعة تعليمية لآله البيانو مُعده عن مؤلفة عالمية ،وبعض المبتدئين فى • العزف على آله البيانو ب-حدو البحث: مؤلفه (HYMNE ALA JOIE) نهايه العصر الكلاسيكى وبدايه العصر الرومانتيكى ع - ادوات البحث: المدونات الموسيقيه - التسجيلات الصوتيه - البيانو - المراجع والرسائل والابحاث العلميه - شبكه الانترنت . مصطاح البحث :

\section{ا الإعداد الموسيقى ( Arrangement)}

هو إعاده صياغة المؤلفات الموسيقية الاصلية بشكل مختلف نسبياً، ويمكن تحديد نوعين من الإعداد الموسيقي؛ اولهما إعداد لأهداف تعليميه محدده ، والاخر إعداد يخص اسلوب العزف على الآله التى تم من اجلها بشكل عام (W.APEL,1950:54,55) Y- المعالجه الموسيقيه (Transcription)

هى احد اشكال الإعداد الموسيقى؛ وهو إعاده كتابه المؤلفات الموسيقيه ،ونقلها من وسيله ادائها الاصليه الى وسيله اخرى، ويقوم بذلك المؤلف الموسيقى الذى يعالج مؤلفاته او مؤلفات غيره من المؤلفين.

اولاً الإطار النظرى :

الإعداد الموسيقى :

وصفت عملية الإعداد الموسيقي على أنها إعادة كتابة المؤلفة الموسيقية من مؤلفة لآلة واحدة إلى مؤلفة موسيقية لآلة أخرى أو لمجموعة آلية كبيرة أو لأوركسترا كاملة، مما يتطلب إضافة توزيع إلى هذه المؤلفة، أو إعادة كتابة المؤلفة الموسيقية الأوركسترالية وتحويلها إلى مؤلفة موسيقية لمجموعة آلية صغيرة أو لآلة منفردة، مما يتطلب حذف بعض الألحان المصاحبة الأقل أهمية، والتركيز على الألحان الرئيسية والأصوات المصاحبة الهامة والفعالة فقط، مع الاحتفاظ 
بالسمات الأساسية للعمل الموسيقي الأصلي بحيث يظل ثابتا دون تغيير (جمعة، وعبد العزيز،

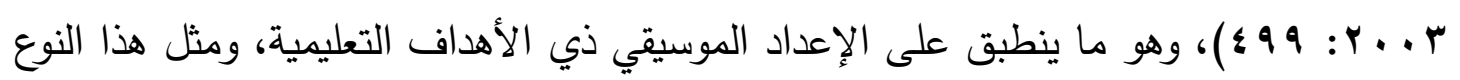

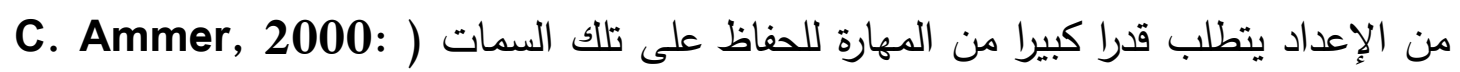

بدأ الإعداد الموسيقي أواخر العصور الوسطى بالمؤلفات المكتوبة لأصوات بشرية

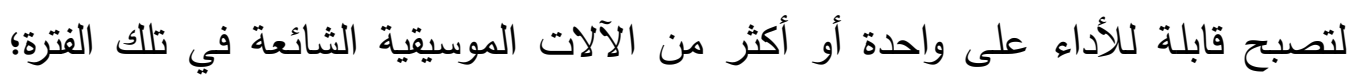

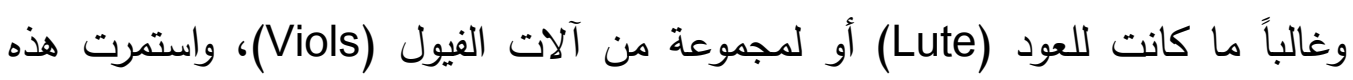
الممارسة على ما هي عليه خلال عصر النهضة "Renaissance" (1600-1450) وما بعده (C. Ammer, 2000: 14). أما مؤلفي عصر الباروك "Baroque" (1750-1600) فقد اتخذوا منحى أكثر تطوراً بهذا الخصوص؛ وكان المؤلف الموسيقي يقوم بإعداد مؤلفاته الخاصة أو مؤلفات غيره

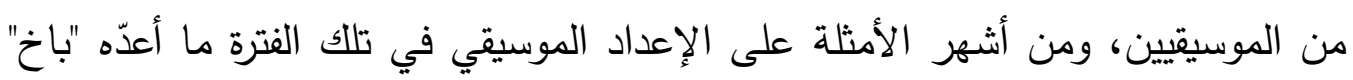
(Bach) للأورغن و الهاربسيكورد من مؤلفات كونشيرتو الكمان لـ "فيفالدي" (Vivaldi)؛ بالإضافة إلى ما أعده من مؤلفاته الخاصة ضمن نفس القالب لأدائها على آلة الهاربسيكورد (14 :C. Ammer, 2000)، وخلال القرن التاسع عشر قام "بيتهوفن" بتطويع كونشيرتو الكمان في سلم ري الكبير (D Major) ليصبح (Beethoven) C. ( كونشيرتو لآلة البيانو، ذلك الإعداد الذي ما زال يُؤدى في بعض الأحيان .(Ammer, 2000: 14

كانت بدايات الإعداد الموسيقي لآلة البيانو من أوبرات، سيمفونيات، ورباعيات وغيرها،

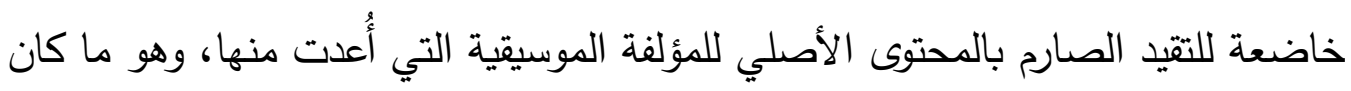

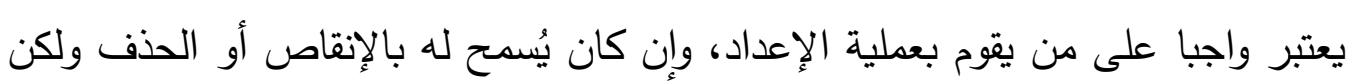

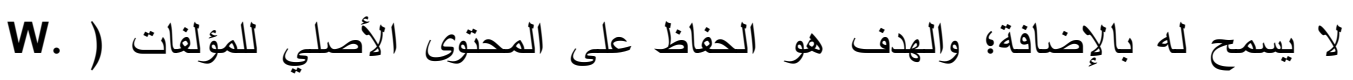
."(APEL, 1950: 54,55

* APEL, WILLI. HARVARD Dictionary of Music, HARVARD UNIVERSITY PRESS, 1950. P 54,55 . 
وفي مرحلة لاحقة؛ أصبحت عملية الإعداد الموسيقي تنطوي على المشاركة الإبداعية

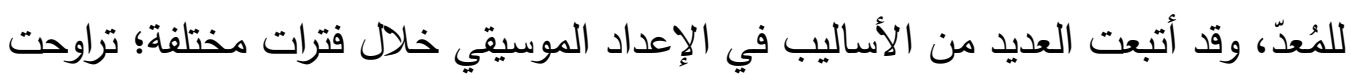

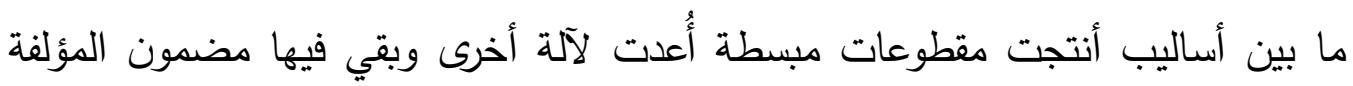
الموسيقية التي أخذت منها على ما هو عليه، وهناك أساليب أنتجت مفطوعات تثكّلت W. ب بعل إعادة الصياغة بشكل كامل للمؤلفة الموسيقية بإضافات وتعديلات شاملة .(APEL, 1950: 54, 55 الإجراءات اللازمة للإعداد الموسيقى : عادة ما ينطوي الإعداد الموسيقي على واحد أو أكثر من الإجراءات الفردية؛ يتم

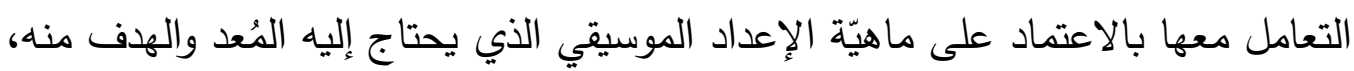

وتتضمن هذه الإجراءات ما يلي (11 - Miller, 2007: 10 (M.

1. إعادة هيكلة المؤلفة الأصلية في نمط موسيقي مختلف (الروك، الجاز وغيرها). r. إعادة هيكلة المؤلفة الأصلية لآلة أو لمجموعة آلات غير تلاك التي كُتبت لها أصلا. r. إضافة مرافقة هارمونية للّحن الموجود في المؤلفة أو معالجة المرافقة الهارمونية الأصلية بما يتناسب والإعداد الجديد.

ء. إنماء اللحن الأصلي عن طريق زيادة عدد الموازير، أو تعزيز الجمل اللحنية بجعها أكثر تعقيداً؛ وذلك بإضافة أنماط ونماذج لحنية وإيقاعية جديدة ๑. إبراز جزئية التفاعل اللحني في المؤلفة الأصلية. 7. تكرار اللحن كاملاً أو جزءا منه؛ ويتضمن هذا التكرار أحد خيارين؛ إما أن يتم

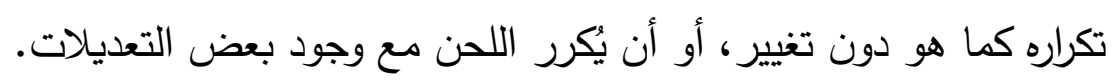

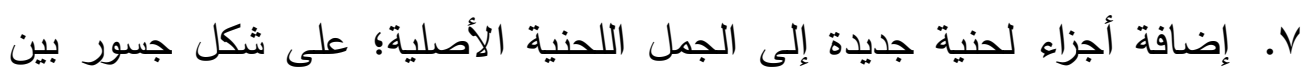
أجزاء اللحن الأصلي. ^. المعالجة الهارمونية للتآلفات المرافقة للحن الأصلي؛ بوضع مرافقة محددة أو الو باختيار أصوات معينة من التآلفات الموجودة والمحافظة عليها كمرافقة هارمونية أساسية في المقطوعة المُعدة. 
- ومن الناحية الهارمونية فإن أحد أهم الشروط الأساسية لأي إعداد موسيقي يكمن في

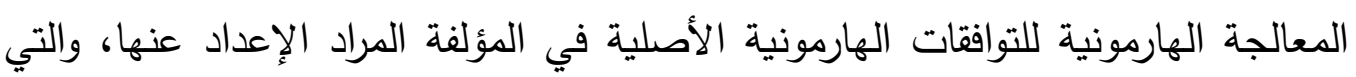
تتضمن تعزيز المرافقة في المواقع الأضعف وتبسيطها هارمونياً في المواقع الأكثر تعقيدا،

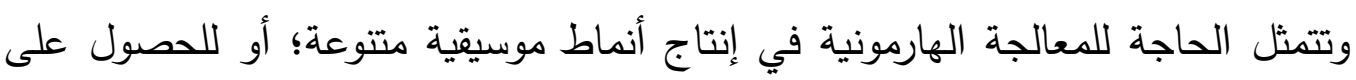
تأثير أو طابع موسيقي معين (D. Grove, 1985: 157)، وهنا تكمن التقنية الثاملة لاختيار المرافقة الهارمونية الأنسب؛ واستخدام المعالجة الهارمونية بالثكل الأمثل في قابلية المعدّ للتعامل هارمونياً مع أي نوع من الألحان وقدرته على المعالجة الهارمونية، الهابه

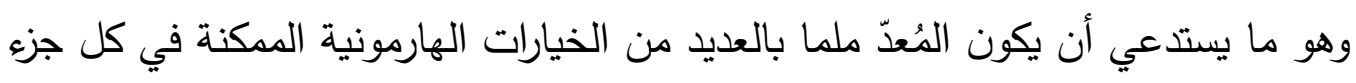
يقوم بإعداده، ومن ثم قدرته على انتقاء أكثر هذه الخيارات ملائمة؛ مما يسهم في تعزيز

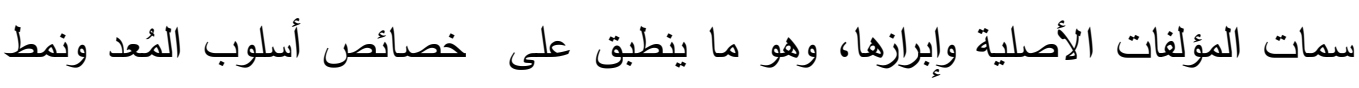

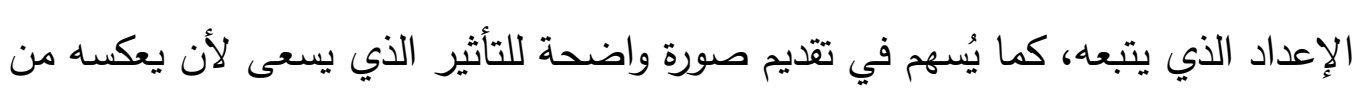

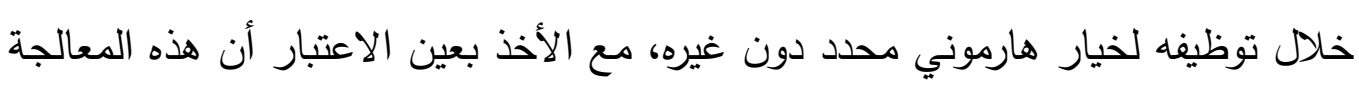

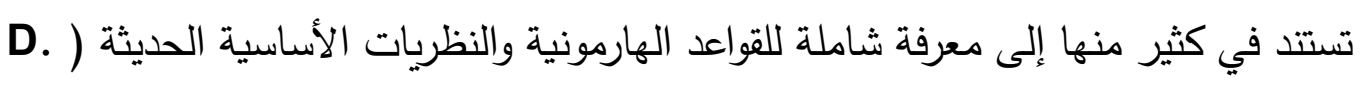

.(Grove, 1985: 157

نبذه عن لودج فان بيتهوفن، (Ludwig van Beethoven) ( نموذجا لنهاية عصر الكلاسيك وبداية عصر الرومانتيك:

موسيقي ألماني، ولد في مدينة (بون)، أظهر دلائل النبوغ الموسيقي في مرحلة عمرية مبكرة؛ فأراد لله والده أن يكون الطفل المعجزة بعد موتسارت، اهتم بتعليمه

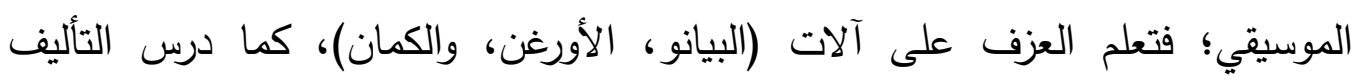
الموسيقي. (فيني، 49191 1: 9 ه ؛ ). أظهرت مؤلفات بيتهوفن المبكرة تأثره بأسلافه من المؤلفين أمثال موتسارت وهايدن،

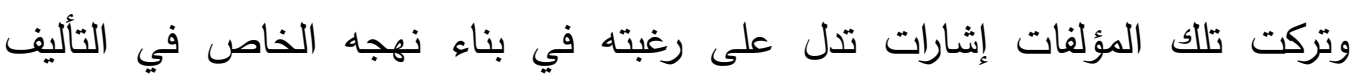

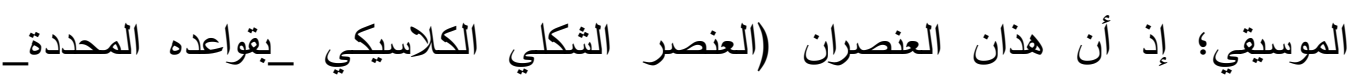
والعنصر التعبيري) ظلا يحركان إنتاج بيتهوفن طوال حياته التي انتهت على أبواب إن لتصني العصر الرومانتيكي، وتتمثل هذه المؤلفات في أعماله من المصنف رقم (1) إلى رقم

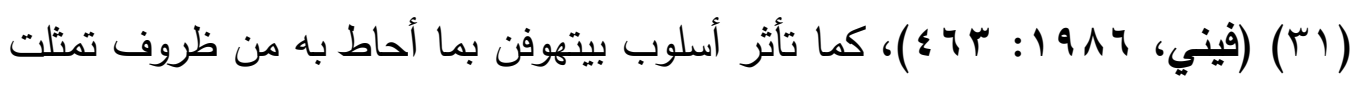


بتزايد مأساة الصمم لديه؛ مما قوّى نزعته الانطوائية، وأصبح يرى في الموسيقى الوسيلة

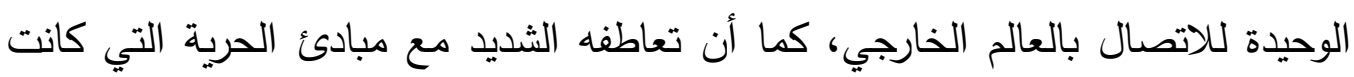
الثورة الفرنسية منطلقا للتعبير عنها؛ وقوة شخصيته وعبقريته كل هذه دفعت به إلى التعبير من خلال مؤلفاته، وساهت في جعله ممثلاً للرومانتيكية في العصر الكلاسيكي (فيني، .$(\leqslant 79: 1919$

تميز بيتهوفن في أسلوبه الخاص المتمثل في إضفائه لمضمون تعبيري على الصيغ

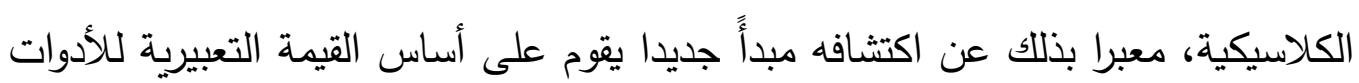
والعناصر الموسيقية؛ دون تفريط في المبادئ الموسيقية التي تعتمد عليها الصيغ

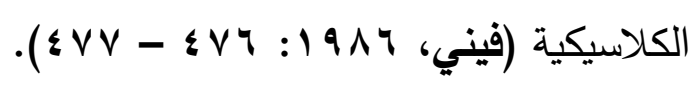

توفي بيتهوفن في فيينا عام VYA ا م، ومن مؤلفاته:

9 سيمفونيات؛ أشهرها الثالثة "البطولية"، الخامسة "القدر"، والتاسعة "الكورالية".

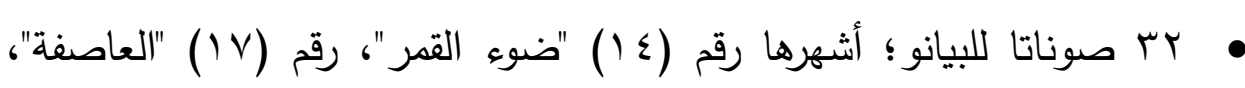

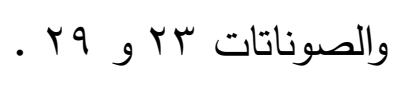

$$
\text { (Egmont) (فتتاحية إيجمونت }
$$

افنتاحية أوبرا فيديليو (Fidelio).

• مقطوعة خفيفة بصيغة "Bagatelle" بعنوان "من أجل إليز" (Für Elise). يتمثل تأثير بيتهوفن على قالب السيمفونية من خلال توسعة الصيغة والكتابة الأوركسترالية؛ حيث أطال في الحركة الأولى كلا من المقدمة (Prelude) والختام (Coda)، كما توسع في قسم التفاعل؛ واستبدل في الحركة الثالثة موسيقى السكيرتسو (Scherzo)

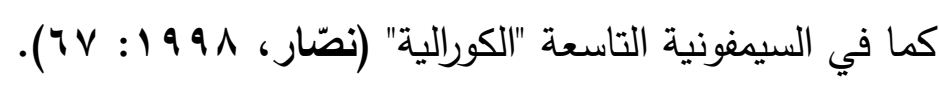
أما بالنسبة للأوركسترا فقد أضاف لها آلات النفخ المتمثلة بالفلوت الصغير (Piccole)، الترومبون، والكونترافاجوت، والآلات الإيقاعية، كما ضاعف عدد آلات الكورنو، وقام بتوسعة قسم الآلات الوترية، ووظف المغنيين المنفردين والكورال في أداء السيمفونية كما

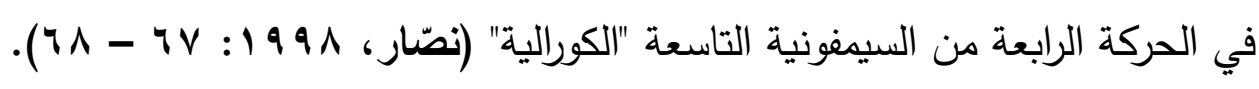
تعد سيمفونيات بيتهوفن (الثالثة، الخامسة، والتاسعة) من أهم ما قدمه بيتهوفن في هذا 
المجال، كما تعتبر الأجزاء الختامية الثلاثة لهذه السيمفونيات أعظم ما كتبه من نموذج

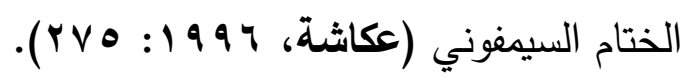

ثانيا الاطار التطيقى ذِّ لقد تحدثا من قبل عن مشكلة البحث واهدافه واهميته وفي هذا الجزء تقوم الباحثه بعرض الدراسه الميدانيه التجريبيه والتى تهدف تحقيق الغرض القائم

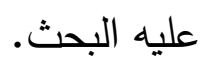
خطوات تنفيذ البرنامج : منهج البحث : اتبعت الباحثه المنهج التجريبي ذو المجموعه الواحده .

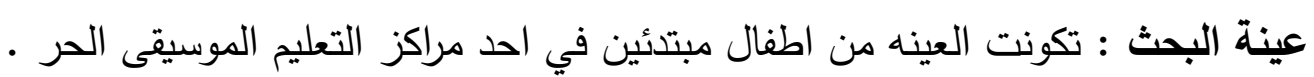
ادوات البحث: مدونات موسيقية ونماذج سمعية ونوت للمقطوعات المُعده لآلة البيانو والتي

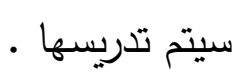

البرنامج والخطوات الاجرائيه للتطبيق :ويقصد هنا بالاجراءات والخطوات المنظمه التى تتمثل فى الوصول بالدارس المبتدئ للاداء الجيد لبعض المؤلفات العالميه المُعده لآلة البيانو (عينة البحث)من خلال اهداف معبره .

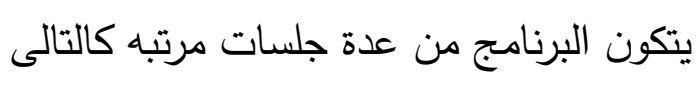
الجلسه الاولى يتم فيها تطبيق الاختبار القبلى التى اجرته الباحثه والجلسه الثانيه يتم فيها تدريس المقطوعه المُعده وشرح المفاهيم الموسيقيه اللازمه للدارس المبتدئ ليجتاز الاختبار

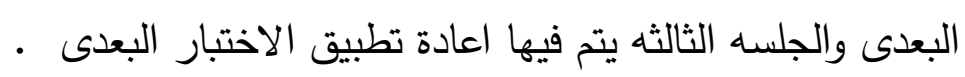
الجلسة الأولى(التعارف وتطبيق الاختبار القبلي/ البعدى)

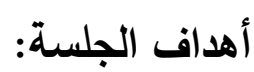
- أن يتعرف أفراد العينة على أهداف وأهمية البرنامج المقترح بشكل عام.

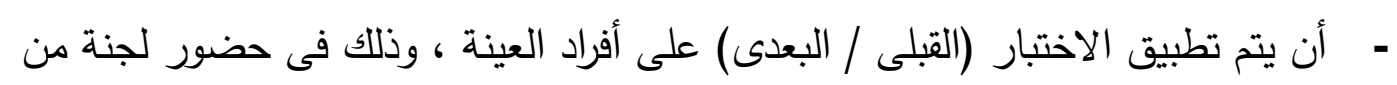

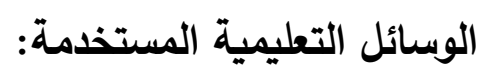
- - موذج الاختبار القبلى / البعدى. 
- أداء كل طالب على حده للتمرينين الموجودين في الاختبار القبلي عزفا (قراءة وهلية)، ثم

وضع الدرجات الخاصة بكل طالب على حده.

التمرين (من وضع الباحثة)

Moderato M.M. $d=108-116$
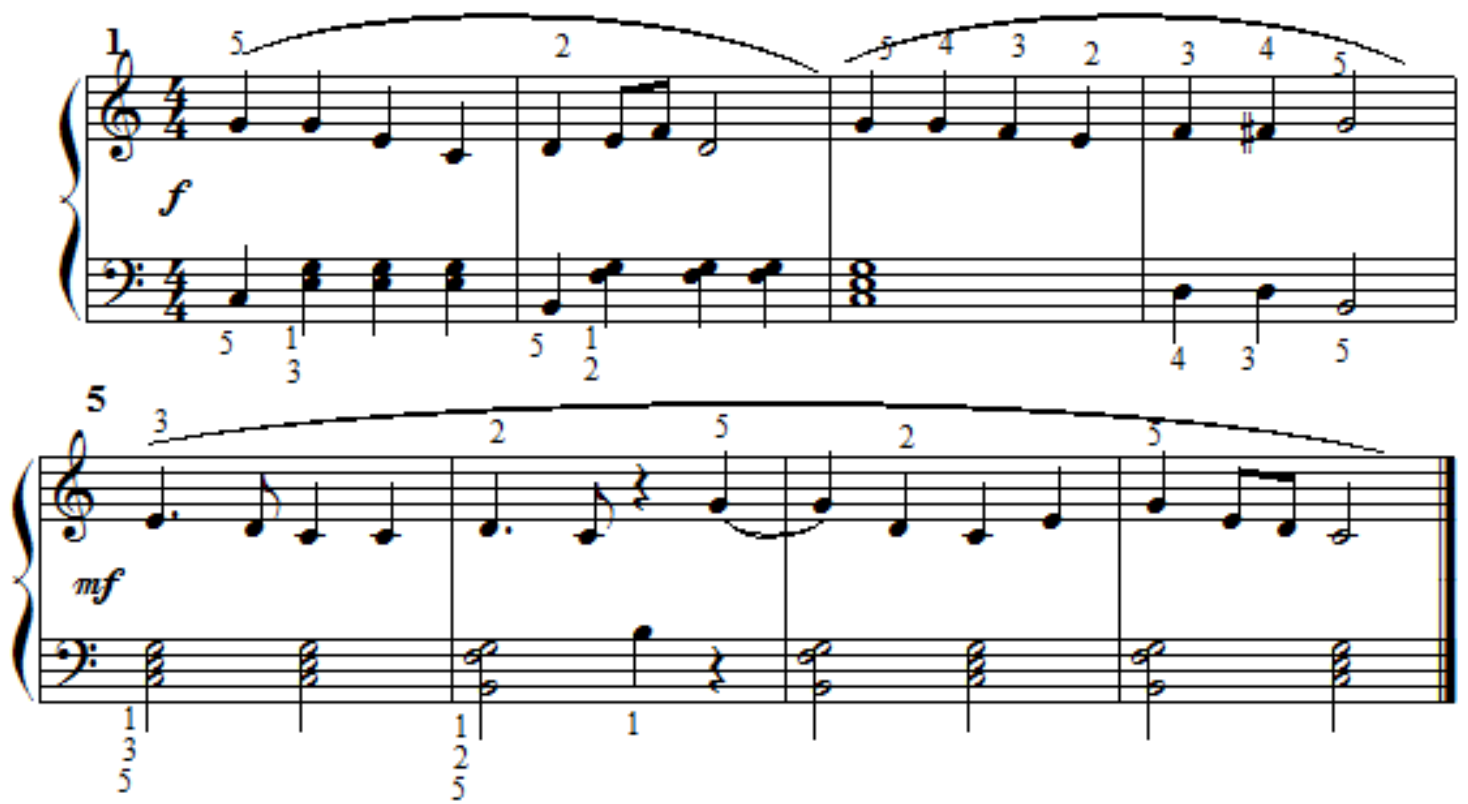

الجلسه الثانية

موضوع الجلسة: الاستفادة من مقطوعة (Hymne ala Joie) والمعدة عن السيمفونية التاسعة لبيتهوفن أولاً من الناحية النظرية. أهداف الدرس:

أن يتعرف الدارس على المفاهيم النظرية التالية: - - ميزان 4/4 ومواضع النبر القوي.

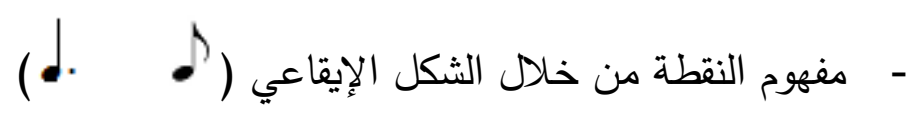
- النفس الموسيقي (La Phrase). - مصطلح السرعة (Moderato). - مصطلحات شدة الصوت ( Forte \& Mezzo Forte). - المسافات الهارمونية (الثانية والثالثة والخامسة والسادسة). 
الوسائل التعليمية المستخدمة:

- تسجيلات صوتية للمقطوعة المُعدة.

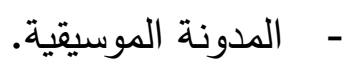

- مادة تعليمية معدة من قبل الباحثة على جهاز الكمبيوتر.

-

طرق التدريس المستخدمة: وهى المقدمة، الأسئلة، العرض، الربط، التطبيق، ثم التقويم وقد استخدمتها الباحثة في جميع الجلسات. الخطوات الإجرائية:

•المقدمة: مناقثة أفراد العينة في المعلومات السابقة لديهم فيما يختص بأهداف الدرس والتي تتحصر في الأسئلة الآتية: ا ـ اذكر ما تعرفه عن ميزان 4/4 ومواضع النبر؟ r. ماذا تعني النقطة خلف الثكل الإيقاعي؟ r. ماذا تعرف عن النفس الموسيقي (La Phrase)؟ ؟. ما المقصود بالمصطلح (Moderato)؟

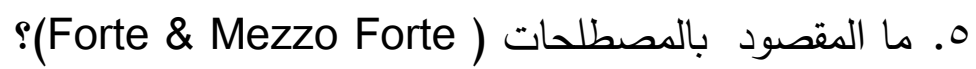
7. ماذا تعرف عن المسافات الهارمونية (الثانية والثالثة والخامسة والسادسة)؟

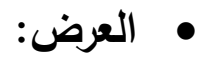

- إعطاء نبذه عن العصر الكلاسيكي، وعن قالب السيمفونية وكذلك نبذة سريعة عن المؤلف الموسيقي (لودج فان بيتهوفن)، مع عرض للمدونة الموسيقية للمقطوعة الدختارة. 


\section{HYMNE A LA JOIE}

de la $9^{e}$ Symphonie
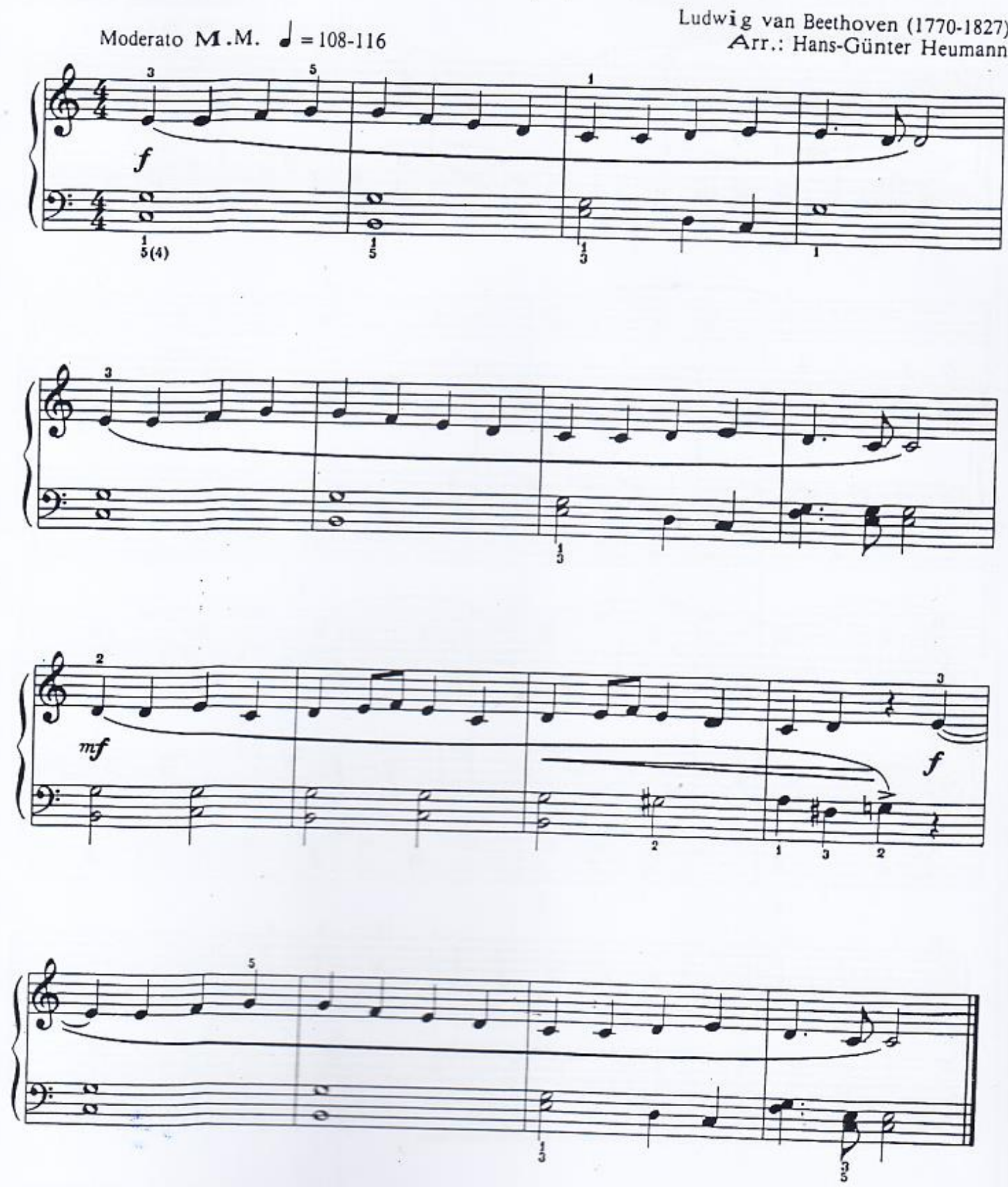

E. Copyright 1986 by BOSWORTH d Ce

Tous droits réserves

\section{- ت توضيح أنواع الموازين البسيطة والتتأكيد على ميزان 4/4:}

وحدة قياس الزمن الموسيقي الوحدة الرئيسية لقياس الزمن الموسيقي (Beat) هي علامة النوار ( م )، وسرعة النوار الطبيعية حوالي من (60:70 Beats) ضربة في الدقيقة، أي ما يعادل نوار واحد كل ثانية، وهي تعادل سرعة ضربات القلب تقريبا. 
يوضح الشكل التالي اختلاف أزمنة الأشكال الإيقاعية نسبة لبعضها البعض

\begin{tabular}{|c|c|}
\hline أُسـماؤها & الأشـكال الزمنية نسبة لبعضها البعض \\
\hline 1 روند whole note & $\mathbf{o}$ \\
\hline 2 half notes بلانش & \\
\hline 4 quarter notes نوار & • \\
\hline
\end{tabular}

(Time signature / Meter) الميزان

يوضع الميزان في بداية المقطوعة الموسيقية، ويتكون من رقمين فوق بعضهما البعض، يدل الرقم الأعلى على عدد الوحدات الزمنية في كل مازورة، ويدل فبالرقم الأسفل على نوع الوحدة المستخدمة في القياس. عدد الوحدات الزمنية في كل مازورة

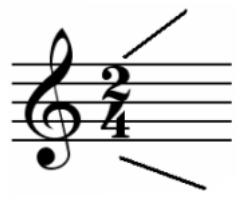

نوع الوحدة الزمنية المُستخدمة في القياس

وتعد أكثر الموازين استخداما الميزان الرباعي 4/4 وهو الميزان المستخدم في المقطوعة المختارة

الميزان الرباعي quadruple meter ويحتوي على أربع علامات نوار في كل مازورة أو ما يعادلها
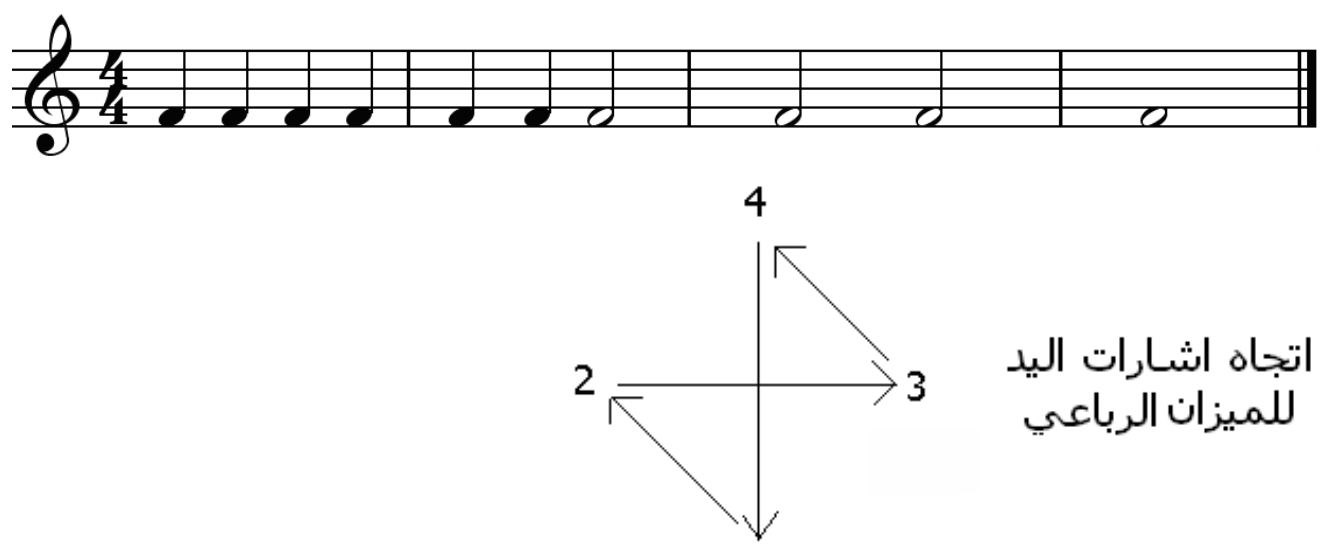

1

المجلد السابع- العدد الثاني- مسلسل العدد (14)- يوليو 2021- الجزء الثالث 
(النبر القوي وإلنبر الضعيف (موضع الضغط - Accent) تبدأ المازورة عادة بنبر (ضغط) قوي على الضربة الأولى من الميزان، وفي الميزان الرباعي يوجد ضغط متوسط على الضربة الثالثة (الوحدة الزمنية الثالثة في المازورة).
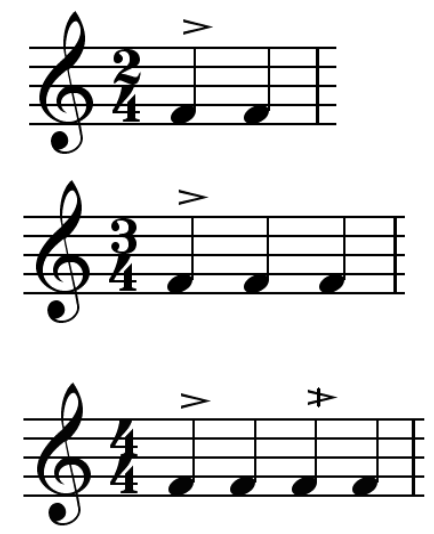

- - توضيح مفهوم النقطة خلف الثكل الإيقاعي: (Dot) النقطة الزمنية

هي نقطة تكتب على يمين العلامة الإيقاعية لتطيل زمنها بمقدار نصف العلامة نفسها، أي أن:

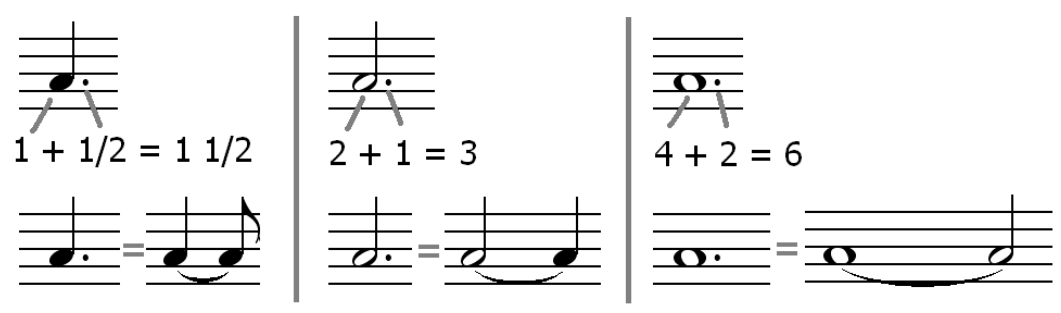

ومن هنا نستتجج أن علامة النوار المنقوط (·ل) والواردة في المقطوعة قيتها الزمنية واحد ونصف نوار • - توضيح مفهوم الجملة الموسيقية، النفس الموسيقي (La Phrase):

Sentence الجملة الموسيقية

الموسيقى لغة تشبه اللغة التي نتحدث بها، فهي تتألف من عبارات (Phrases) وجمل (Sentences) الموسيقية، كما تتجمع الجمل الموسيقية لتصيخ الفقرة الموسيقية، وتتألف الجملة الموسيقية المنتظمة من عبارتين كل عبارة منها تتكون من 4 مازورات، تتتهي العبارة الأولى بققلة نصفية لتعطي الإحساس بعدم اكتمال الجملة الموسيقية وتوقع الاستمرار، أما (half cadence) 
العبارة الثانية فتتنهي بقفلة تامة لتعطي الإحساس بانتهاء الجملة الموسيقية Perfect) .cadence)

عبارة تتكون من ؛ مازورات عبارة تتكون من ؛ مازورات

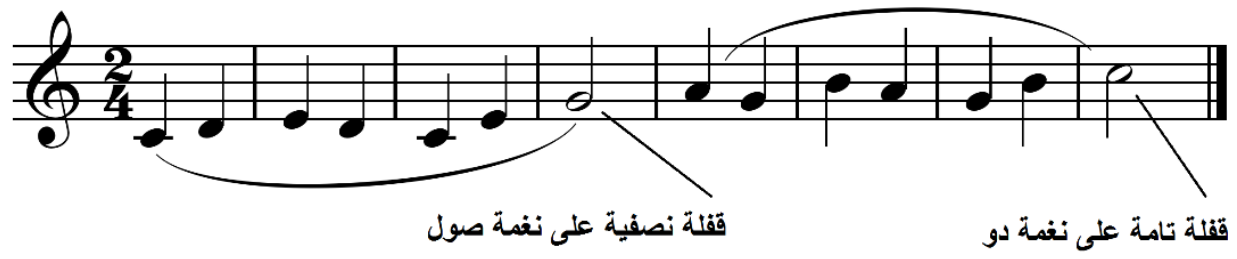
نموذج آخر للجملة الموسيقية المنتظمة
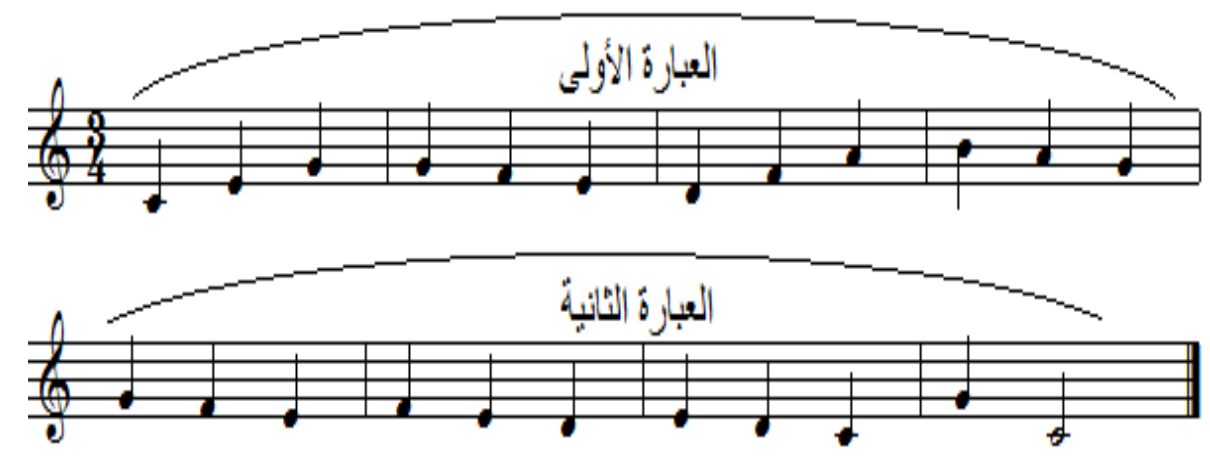
- - توضيح مفهوم مصطلحات السرعة:

- مصطلحات خاصة بالسرعة Tempo

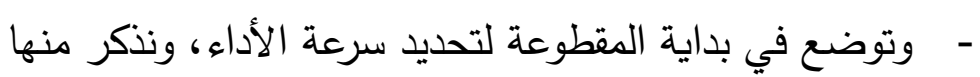

\begin{tabular}{|r|r|}
\hline معنى المصطلح & سريع المصطلح (بالإيطالية) معتدل \\
\hline Allegro & مائل إلى البطء \\
\hline Moderato & Andante \\
\hline
\end{tabular}

- ويمكن تحديد السرعة المطلوبة بدقة أكثر من خلال كتابة سرعة النوار في بداية المقطوعة الموسيقية، ويكتب ذلك عادة فوق الميزان، كما يلي

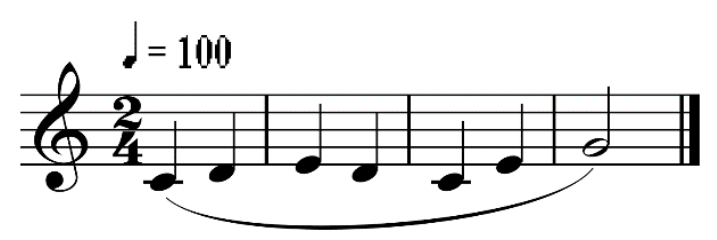


- وهذا يعني أن سرعة النوار تساوي (100) ضربة في الدقيقة الواحدة، ويتم تحديد ذلك بدقة عن طريق جهاز المترونوم (Metronome) والذي اخترعه الألماني مايلزيل عام 11/10 التحديد عدد الضربات (Beats) في الدقيقة الواحدة. (Maelzel)

- توضيح مفهوم المصطلحات ( Forte \& Mezzo Forte): - مصطلحات خاصة بالتعبيز (Expression)

- تتخلل المدونة الموسيقية للمقطوعة المختارة بعض المصطلحات الخاصة بالأداء نذكرها

\begin{tabular}{|c|c|c|}
\hline الاسم الإيطالي & الشكل المختصر للمصطلح & معنى المصطلح \\
\hline Forte & $\mathrm{F}$ & الأداء بصوت قوي \\
\hline mezzo forte & Mf & الأداء بصوت متوسط القوة \\
\hline mezzo piano & $\mathrm{Mp}$ & الأداء بصوت متوسط الضعف \\
\hline Piano & $\mathrm{P}$ & الأداء بصوت ضعيف \\
\hline
\end{tabular}

-

Intervals المسافات

يسمى البعد بين نغمتين "مسافة" (Interval). وتحسب المسافة برقم يدل على عدد النغمات بين نغمتي المسافة بدءاً من نغمة البداية حتى النغمة التي تنتهي عندها المسافة. وهناك مسافات Harmonic نسمع فيها النغمتين بالتتالي، ومسافات هارمونية Melodic intervals ميلودية intervals

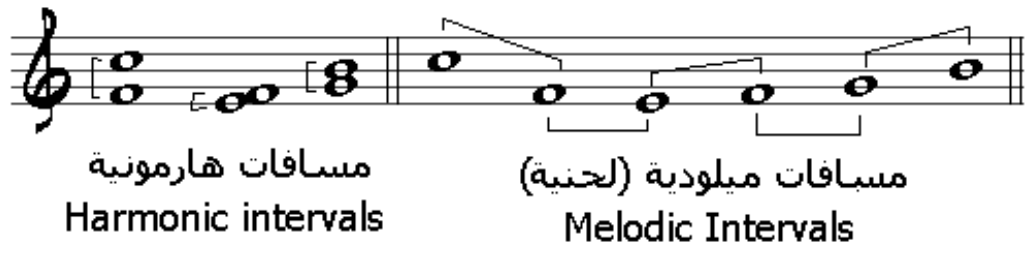

توضيح المسافات بدءاً من نغمة دو باستخدام المسافات اللحنية Melodic Intervals:

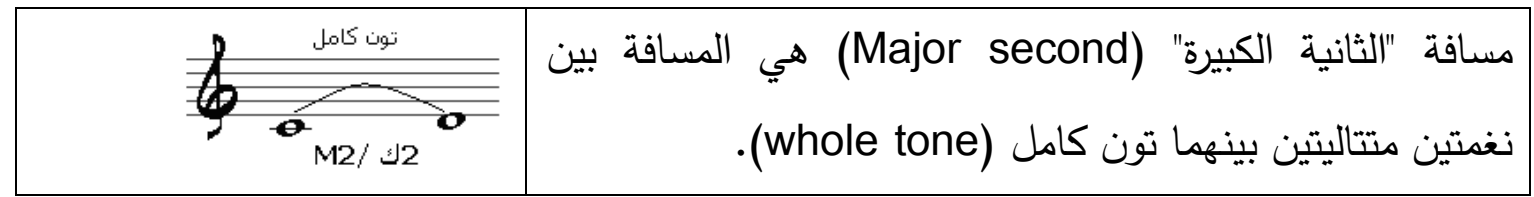




\begin{tabular}{|c|c|}
\hline 它 & مسافة "الثانية الصغيرة" (minor second) هي المسافة بين \\
\hline 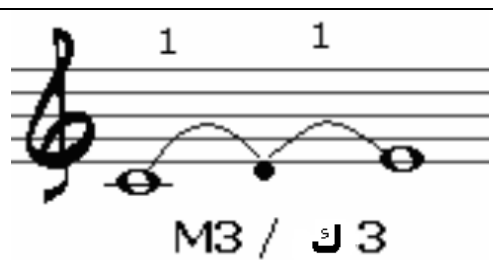 & مسافة "الثالثة الكبيرة" (Major third) هي المسافة بين نغدتين \\
\hline $\mathrm{m}_{1 / 2}^{b /}$ & 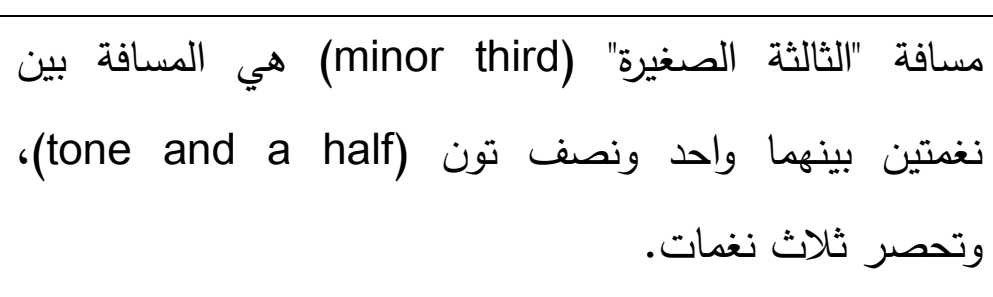 \\
\hline$\overbrace{\mathrm{P} 4 / \mathrm{V}_{1 / 2}^{1}}^{1}$ & مسافة "الرابعة التامة" (Perfect fourth) هي المسافة بين \\
\hline$b_{0}^{1} \underbrace{1}_{1 / 2}$ & 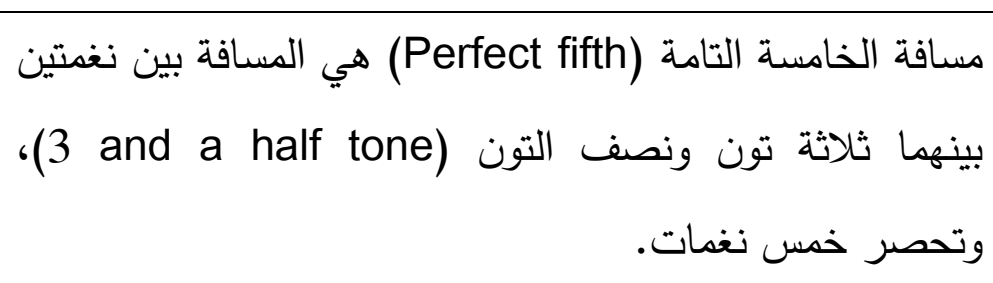 \\
\hline 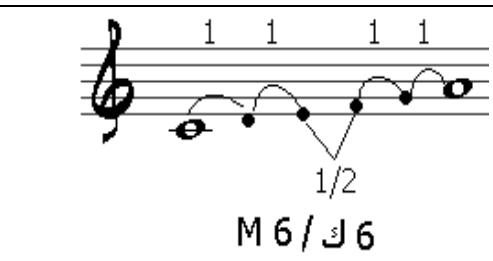 & مسافة السادسة الكبيرة (Major sixth) بين نغتيها أربعة تون \\
\hline$\oiint^{11 \frac{1}{\sigma \cdot \sigma \cdot V_{1 / 2}^{1 / 2}}}$ & 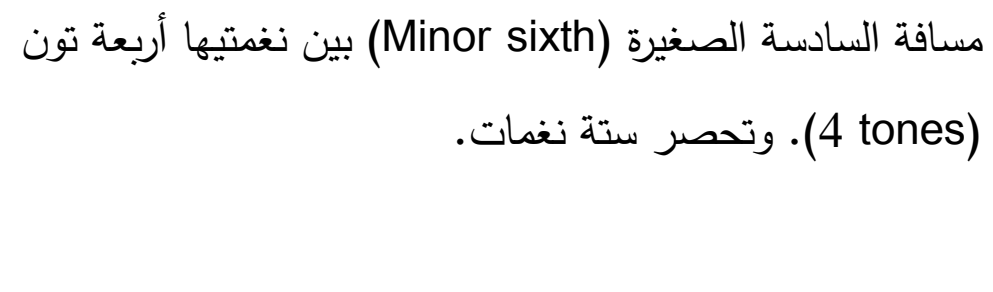 \\
\hline 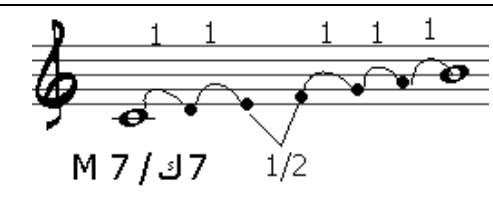 & 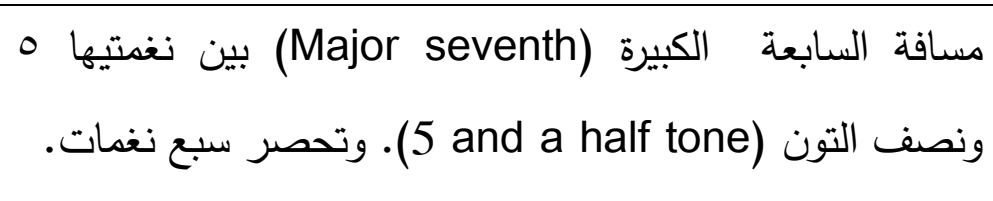 \\
\hline
\end{tabular}




\begin{tabular}{|c|c|}
\hline 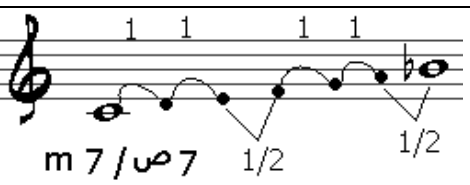 & 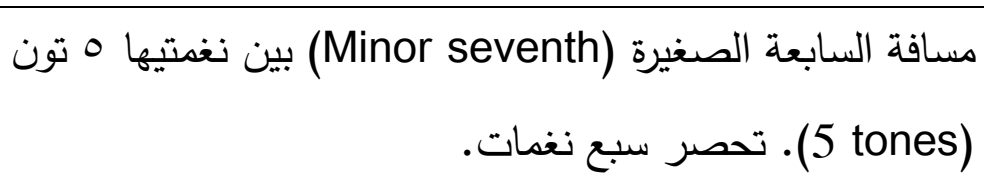 \\
\hline 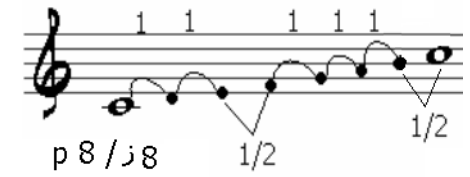 & 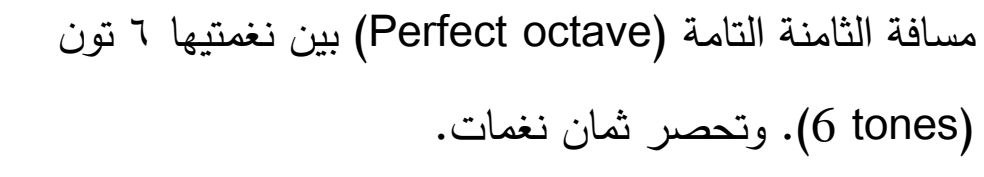 \\
\hline
\end{tabular}

علماً بأن المسافة اللحنية Melodic interval تكون صاعدة إذا كانت تتجه للنغمة الحادة. وبالعكس، تكون المسافة هابطة إذا كانت تتجه للنغمة الغليظة. أما المسافات الهارمونية فتكون إما متتافرة أو متوافقة أو تامة التوافق وذلك تبعاً لنوعية الصوت الصادر عنها كما هو مبين في الجدول التالي (تم وضع (*) بجوار المسافات الهارمونية الواردة في المقطوعة المختارة):

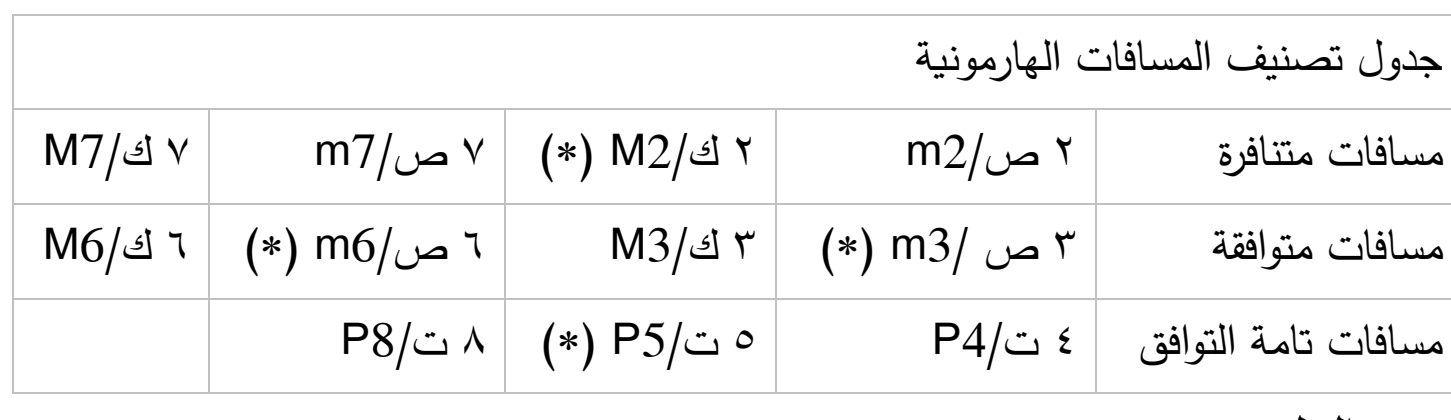

\section{التطبيق:}

تطلب الباحثة من أفراد العينة ما يأتي:

- دون ع مازورات لحنية في سلم دو الكبير في ميزان 4/4 على أن يتضمن علامات

إيقاعية منقوطة.

- اقسم التمرين الذي قمت بتدوينه إلى جزأين متساويين باستخدام النفس الموسيقي. - ضع سرعة محددة للتمرين في ضوء ما درست. - أضف التعبير المناسب لكل جزأ من حيث شدة الصوت في ضوء ما درست. التقويم:

- لم تظهر صعوبات أمام أفراد العينة، واستطاع الجميع الإجابة على جميع الأسئلة. الجلسه الثالثه تطبيق الاختبار البعدي - يتم تطبيق الاختبار (القبلى / البعدى) على أفراد العينة، وذلك فى حضور لجنة من الأساتذة المتخصصين الذين قاموا بتقييم العينة في الاختبار القبلي. 
الو الوسائل التعليمية المستخدمة:

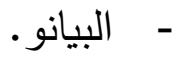

- - منوذج الاختبار القبلى / البعدى.

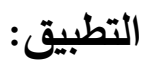

- - أداء كل طالب على حده للتمرينين الموجودين في الاختبار البعدي عزفا (قراءة وهلية)، ثم

وضع الدرجات الخاصة بكل طالب على حده.

-

اعتبر الاختبار بالنسبة لأفراد العينة سهلا وفي حدود مستواهم المعرفي والأدائي.

نتائج البحث عبر الاساليب الإحصائيه اللازمه :

مناقثة النتائج الخاصه بمقطوعه Hymne ala Joie

لقد أجرت الباحثة اختبار ويلكوكسن اللا معلمي لعينتين تابعتين وتوصلت للنتائج الآتية :

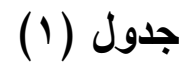

\begin{tabular}{|r|r|r|r|r|r|}
\hline \multicolumn{3}{|c|}{ Descriptive Statistics } \\
\hline $\begin{array}{r}\text { Std. } \\
\text { Deviation }\end{array}$ & Mean & Maximum & Minimum & $\mathrm{N}$ & \\
\hline 1.069 & 5.86 & 7 & 4 & 7 & $\begin{array}{r}\text { الأولى قبلي } \\
\hline 0.816\end{array}$ \\
\hline
\end{tabular}




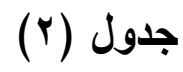

\begin{tabular}{|c|c|}
\hline \multicolumn{2}{|r|}{ Test Statistics $^{a}$} \\
\hline المقطوعة الأولى بعدي - & \\
\hline$-2.375^{-b}$ & Z \\
\hline 0.018 & Asymp. Sig. (2-tailed) \\
\hline \multicolumn{2}{|c|}{ a. Wilcoxon Signed Ranks Test } \\
\hline
\end{tabular}

من الجدول السابق يمكنتا ملاحظة أن :

قيمة (2-tailed (2 ( نرفض الفرض العدمي أي أنه توجد فروق ذات دلالة إحصائية بين متوسطات درجات الدارسين عينة البحث فى الاختبار القبلي / البعدي. وبالنظر إلى جدول (1) نلاحظ أن متوسط درجات الدارسين عينة البحث فى الاختبار القبلي

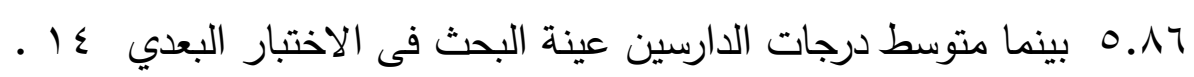
و من ثم فإن الفروق لصالح الاختبار البعدي. نقبل الفرضية الأولي والتى تتص على أنه "توجد فروق ذات دلالة إحصائية بين متوسطات درجات الدارسين عينة البحث فى الاختبار القبلي / البعدي لصالح الاختبار البعدي الخاص بهذه المقطوعة.

توصيات البحث :

1. تتمية مهارات الدارس المبتدئ في العزف على آلة البيانو من خلال المقطوعات المُعدة

$$
\text { (عينة الدراسة). }
$$

r. دراسة وتحليل أكبر قدر من المقطوعات الئعدة لآلة البيانو، والاستفادة منها.

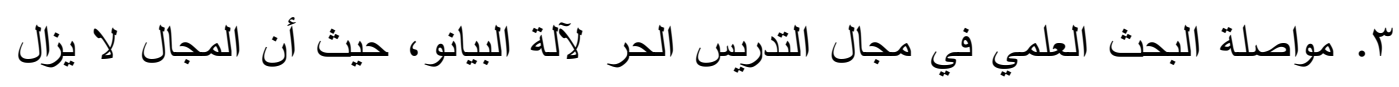
خصباً للعديد من الأبحاث العلمية. 
اولا:المراجع العربية:

1. جمعة، سامي. وعبد العزيز، ميرفت. r .. بام. الاستفادة من بعض الألحان العالمية في

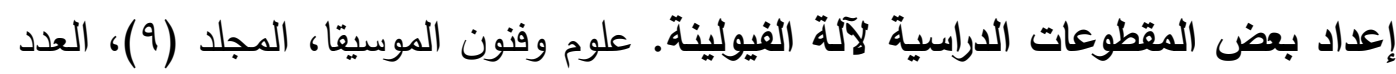

r. فيني، ثيودور • 91 ام. تاريخ الموسيقا العالمية. ترجمة: الخولي، سمحة. وعبد الرحيم، محمد جمال. دار المعرفة، القاهرة. r. نصار، زين. 991 ام. عالم الموسيقا. الهيئة المصرية العامة للكتاب، القاهرة.

ثانيا: المراجع الاجنبية:

Ammer, C. 2004. The Facts On File Dictionary of Music. New York, USA.

Miller, M. 2007. Arranging and Orchestration. New York, USA.

Grove, D. 1985. Arranging Concepts Complete. Alfred Publishing Co., Inc., USA.

APEL, W. 1950. Harvard Dictionary of Music. Harvard University Press, Cambridge, UK. 


\section{A study of some works prepared for the piano and its importance in teaching for the novice student}

\section{Research Summary:}

Music is the language of feeling and feeling, and it is considered one of the fine arts through which a person expresses his innermost self and his vision of things. Learning, this study aims to address some prepared pieces with specific educational goals as guiding models in guiding the novice learner on the piano towards investing the international pieces that have been prepared specifically for playing the piano to achieve the maximum benefit, and also aims to entice the novice learner To study international music and play the piano by applying a study program through which the novice learner reaches the required technical performance. 